\title{
Investigation of ground behaviour adjacent to an embedded pile according to various tunnel volume losses
}

\author{
Suk-Min Kong ${ }^{1}$, Hyuk-Sang Jung ${ }^{2}$ and Yong-Joo Lee ${ }^{1^{*}}$
}

*Correspondence:
ucesyjl@seoultech.ac.kr
${ }^{1}$ Department of Civil
Engineering, Seoul National
University of Science
and Technology, 232
Gongneung-ro, Nowon-gu,
Seoul 139-743, South Korea
Full list of author information
is available at the end of the
article

${ }^{*}$ Correspondence: ucesyj|@seoultech.ac.kr Engineering, Seoul National University of Science and Technology, 232 Gongneung-ro, Nowon-gu, article

\begin{abstract}
The rapid development of urban areas due to population and infrastructure growth has led to increased traffic congestion, greater demand for residential space and environmental issues. One solution for these problems is the development of underground space, especially tunnelling. However, tunnel collapse causes significant damage, so it is important to understand the interactive behaviour of soil-structure-tunnelling in urban areas. This study uses a model test to investigate the behaviour of an embedded pile and the surrounding ground due to tunnelling in soft ground. Tunnelling is simulated by volume loss $\left(V_{L}\right)$, and soil deformation is observed according to $V_{L} u$ sing close range photogrammetry and image processing. These data are compared by $3 \mathrm{D}$ numerical analysis.
\end{abstract}

Keywords: Tunnelling, Embedded pile, Model test, Close range photogrammetry, 3D numerical analysis

\section{Background}

The rapid development of urban areas has resulted in a lack of surface space, increased traffic congestion and pollution. To address these problems of urbanization, underground space is often developed. Thus, many studies concerning tunnels and ground behaviour have been carried out. Lee [1] conducted a model test with 20 cases according to the location of piles in two-dimensional plane-strain conditions. Aluminium rods were used to describe ground as soil particle material. Also, cylinder equipment that could be reduced in diameter was devised. Also, these results were compared with close range photogrammetry and numerical analysis. The close range photogrammetry was proved to be useful for analyzing the behavior of ground. The author suggested an influence line that is larger than the existing study indicating the zone of soil within which the pile will be affected. Lee [2] investigated the behaviour of single and grouped piles due to tunnelling in weathered rock using the 3D finite element method (FEM). The author measured the rapid change of the pile axial force due to tunnelling. Settlements by grouped piles were found to generate greater settlements than settlements by single piles. Also, these settlements cause larger relative displacements and shear strains in boundary between pile and ground. Grouped piles were found to generate greater settlements than single piles. Yoo [3] analysed the interactive behaviour of ground and piers due to tunnelling using 3D numerical analysis.

(c) The Author(s) 2017. This article is distributed under the terms of the Creative Commons Attribution 4.0 International License (http://creativecommons.org/licenses/by/4.0/), which permits unrestricted use, distribution, and reproduction in any medium, provided you give appropriate credit to the original author(s) and the source, provide a link to the Creative Commons license, and indicate if changes were made. 
This showed significant losses of the bearing capacity of piles occurred directly above the tunnel during tunnelling. But, the pile tip settlement decreases with increasing the lateral distance between the tunnel and a pile, and becomes negligible when $2.0 \mathrm{D}$, indicating that the effect of the tunneling on piles located laterally beyond 2.0D from the tunnel may be ignored. Mair and Williamson [4] performed centrifuge model tests regarding the effects of tunnelling beneath bored piles in clay. The centrifuge modelling showed that a single pile above the tunnel centreline settles by a greater amount than the ground surface settlement. Also, the results showed a reduction in skin friction acting on a pile when it is subjected to negative relative displacements and an increase in skin friction when it is subjected to positive relative displacement. Giardina et al. [5] analyzed ground surface settlement due to tunnel excavation according to foundation height. Andrea et al. [6] illustrated how piled foundations increase the risk of structural damage compared to shallow foundations, whereas structural stiffness can reduce building deformations. Flexural deformations are predominantly induced by tunnel excavations beneath piles, whereas horizontal strains at ground level are negligible when a continuous foundation is included. Therefore, this study investigates settlement of pile and ground surface, and the axial force of an embedded pile according to the offset between the pile tip and tunnel crown by model test. Soil behaviour due to tunnelling is analyzed by close range photogrammetry and the results are compared using the 3D FEM back analysis.

\section{Model test}

In this study, a model test is conducted to measure soil deformation. Tunnelling equipment is devised for the model test and the tunnelling is simulated through volume loss $\left(V_{L}\right)$ in a model tunnel. Settlements of pile and ground surface are measured with a dial gauge. At the same time, deformation of the ground is observed by close range photogrammetry and image processing.

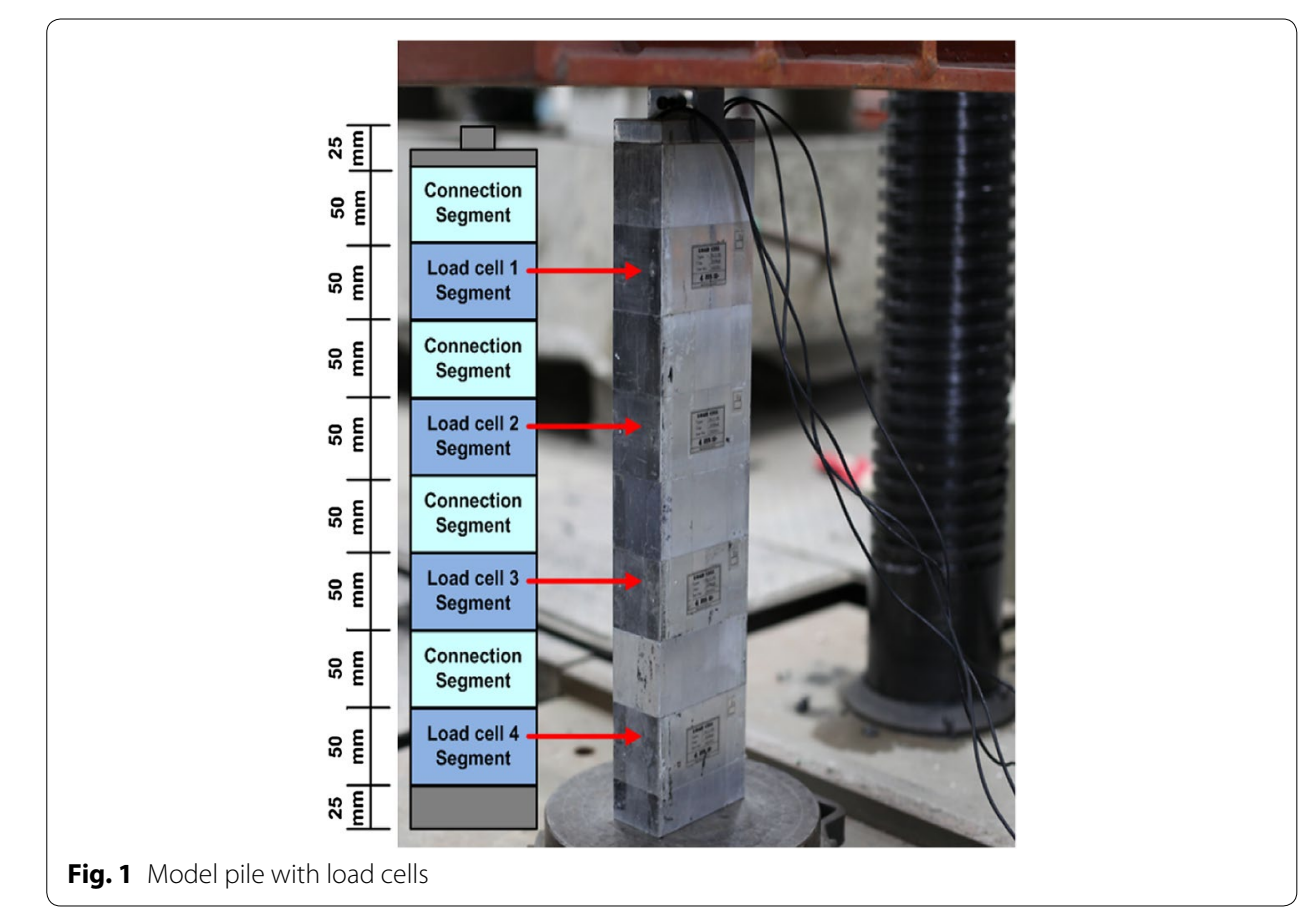




\section{Equipment for the model test}

The container for the model test is a rigid, rectangular steel frame $(1500 \mathrm{~mm} \times 1000 \mathrm{~mm} \times 100 \mathrm{~mm})$. The front of the container is composed of acrylic to show soil deformation. Sand raining equipment is installed on top of the container. Figure 1 shows a model pile, which measures $50 \mathrm{~mm} \times 100 \mathrm{~mm} \times 450 \mathrm{~mm}$ (length $\times$ width $\times$ height). The model pile consists of 4 load cell segments and 4 connection segments. Strains of each segments are measured by the load cells. The connection segments are placed between the load cell segments. The diameter of actual steel single piles is between 500 and $1200 \mathrm{~mm}$. Thus, this is a $1 / 10$ reduction size of the real tunnel diameter. For convenience in the model test, two rows of grouped piles are idealized as a single column, which has the equivalent parameter of the grouped pile [7]. Figure 2 shows the idealized model pile. However, the pile cap is not considered in this study. A model tunnel is designed for this study as shown in Fig. 3a. The model tunnel has a $100 \mathrm{~mm}$ diameter and is installed $200 \mathrm{~mm}$ from the bottom of the container. Volume loss $\left(\mathrm{V}_{\mathrm{L}}\right)$ of the model tunnel is controlled using a hydraulic pump (Fig. 3b). Lee and Lee [8] calibration for the correlation between water, tunnel diameter, and $\mathrm{V}_{\mathrm{L}}$ is used. The layout of the model test equipment is shown in Fig. 4.

\section{Calibration for the model pile}

The calibration was carried out three times to measure the strain of pile segments using a Universal Testing Machine (UTM), as shown in Fig. 5. According to the increase of loads, the strain is linearly increased (Fig. 6). In this study, empirical equations for

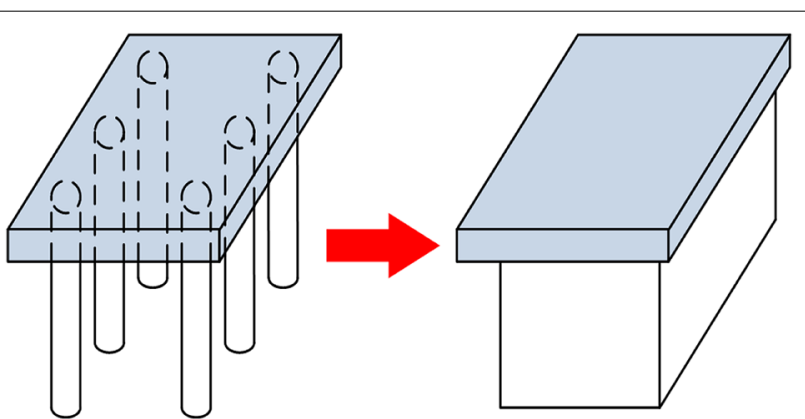

Fig. 2 Grouped pile idealized as single column

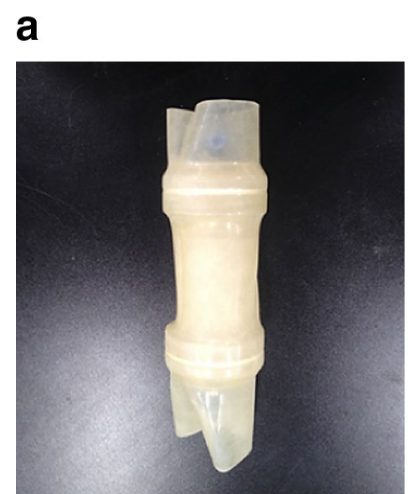

b

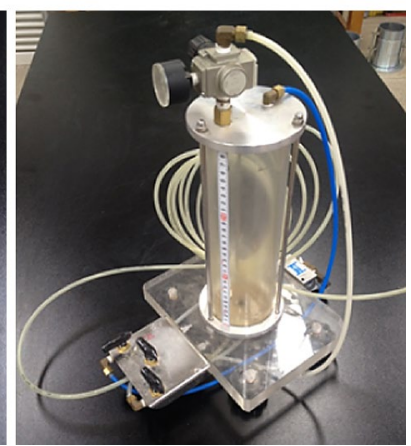

Fig. 3 Tunnelling device: a model tunnel; b hydraulic pump 


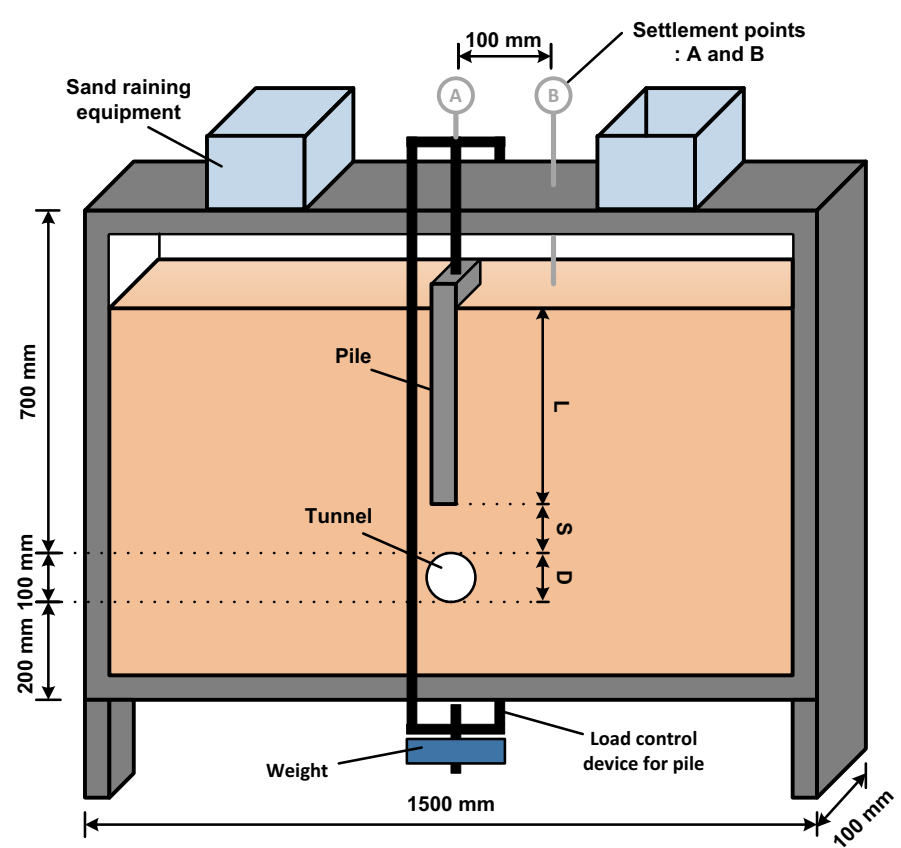

Fig. 4 Layout of model test equipment with settlement point $A$ and $B$

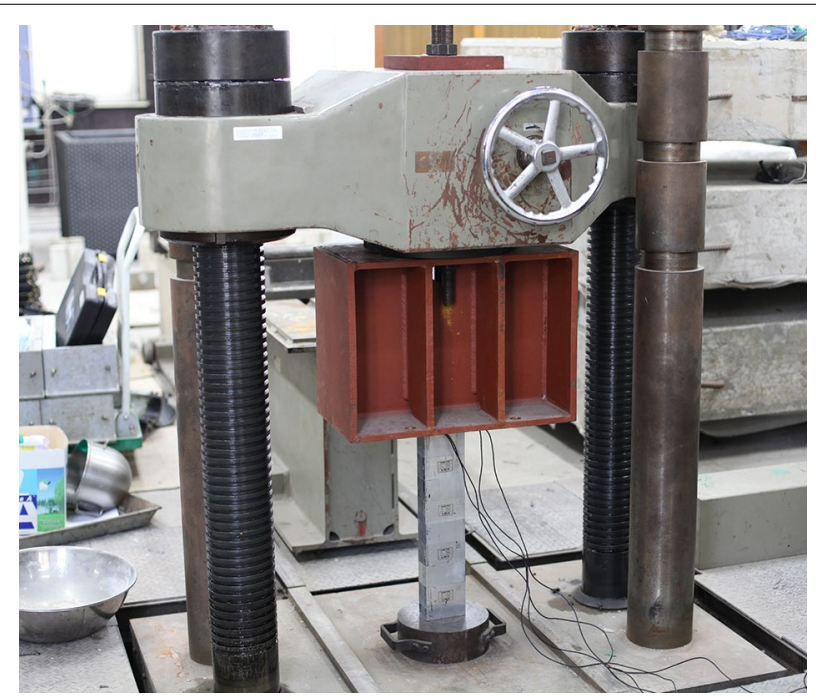

Fig. 5 UTM calibration of the model pile

load(y)-strain(x) are gained. Equations (1), (2), (3), and (4) are obtained from each segment as below:

Segment $1: \mathrm{y}=0.0122 \mathrm{x}-0.0643$

Segment $2: \mathrm{y}=0.0107 \mathrm{x}-0.0146$ 
Segment $3: \mathrm{y}=0.0120 \mathrm{x}-0.0450$

Segment $4: \mathrm{y}=0.0127 \mathrm{x}-0.0813$

\section{Process of the model test}

The procedure of the model test is as follows:

a. The container, model pile, and model tunnel are prepared.

b. The container is filled with black sand up until the position of the model tunnel. The sand raining equipment is used to homogenize the model ground. However, compaction is not conducted.

c. The model tunnel is installed in the planned position. The hydraulic pump is used to set the initial diameter of tunnel.

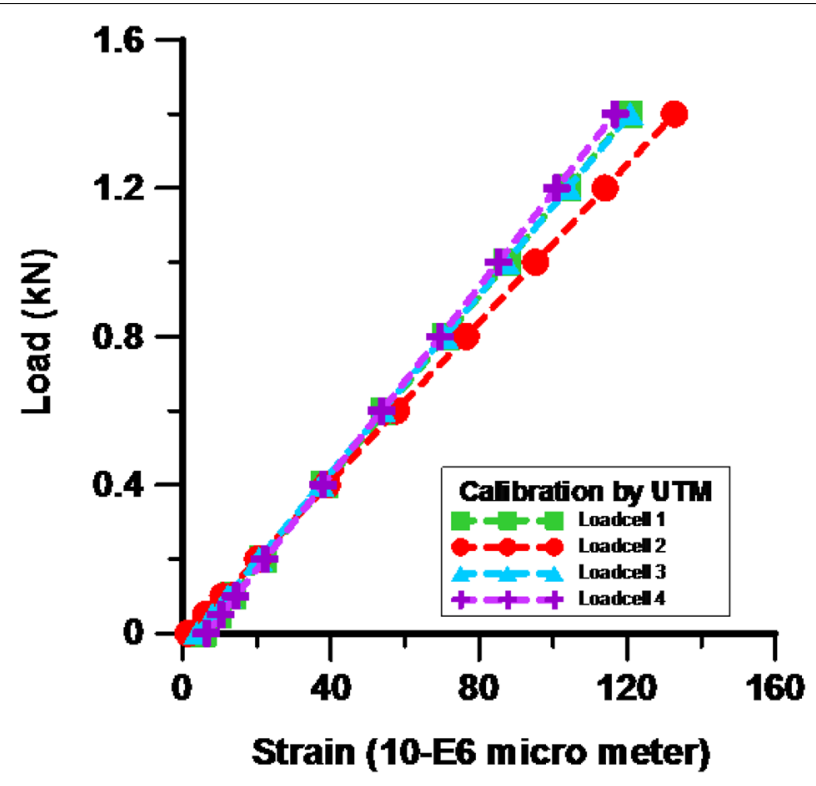

Fig. 6 Results of UTM calibration

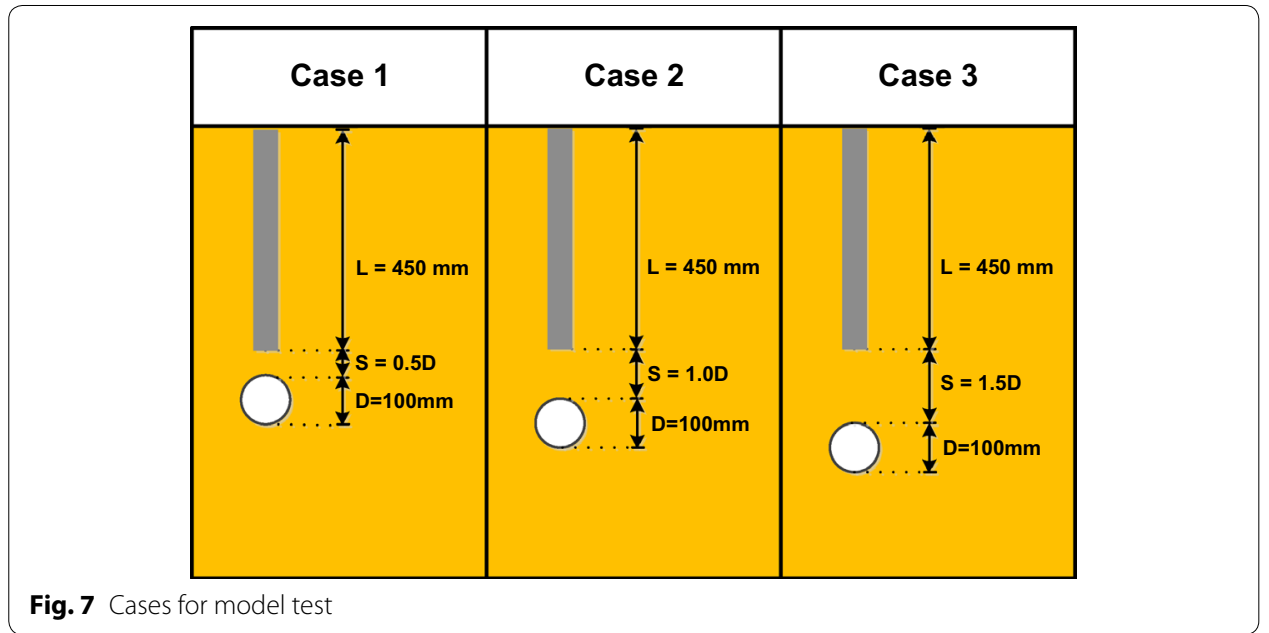


d. The model pile is installed and each of the segments are connected to the data logger. Then, the model test is carried out in three cases according to the offset between the pile tip and tunnel crown, as shown in Fig. 7.

e. The container is filled with black sand up until the ground surface. Dial gauges are set at the centre of the model pile top and ground surface (points A and B).

f. The diameter of the model tunnel is gradually reduced as a result of $V_{L}$ from the hydraulic pump.

g. Axial forces and settlements are measured using a data logger and dial gauge.

\section{Close range photogrammetry}

Close range photogrammetry is a technique for obtaining image data. Figure 8a shows the method of close range photogrammetry. Aluminum rods (5 $\mathrm{mm}$ diameter) and a Canon EOS 5D Mark II are used for the close range photogrammetry. A circle shaped reflective point ( $3 \mathrm{~mm}$ in diameter) is attached to the end of the aluminium rods. These aluminium rods are inserted into sandy ground. Figure $8 \mathrm{~b}$ shows the final setup of the close range photogrammetry. The aluminium rods are moved with the surrounding soil during tunnelling and captured by the Canon EOS 5D Mark II. Four types of image data are obtained from various angles and positions: from the centre, the left side and right sides, and at a $90^{\circ}$ rotation.

\section{Image processing}

The image data are analysed using image processing. First, the image data is classified according to various steps of $\mathrm{V}_{\mathrm{L}}$. Each file is named from Epoch_0 to Epoch_4. Epoch_0 is noted as the initial state $\left(\mathrm{V}_{\mathrm{L}}=0 \%\right)$. These image file groups are analysed by a Vision Measurement System (VMS) program, as shown in Fig. 9a. A total of 18 control points

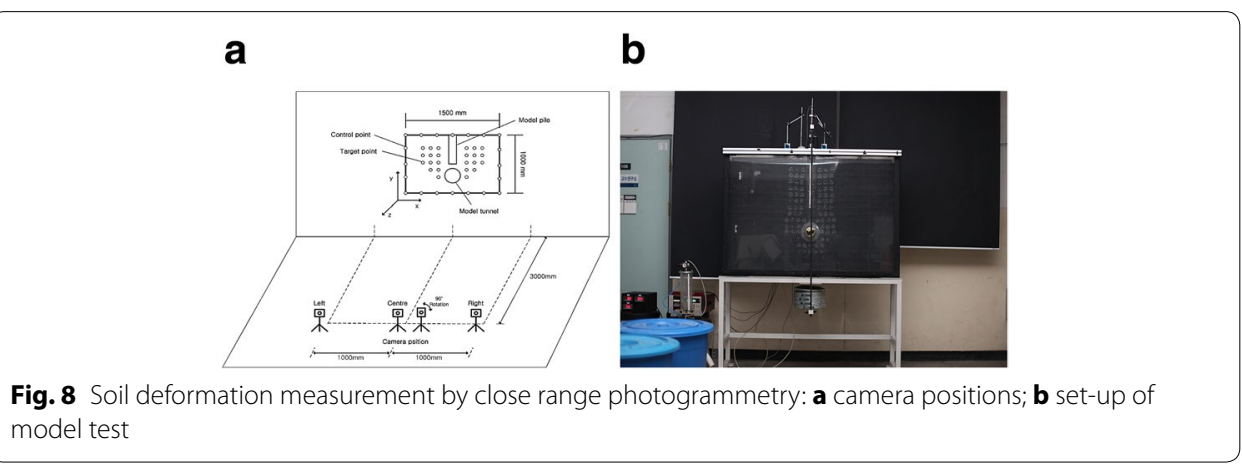

a

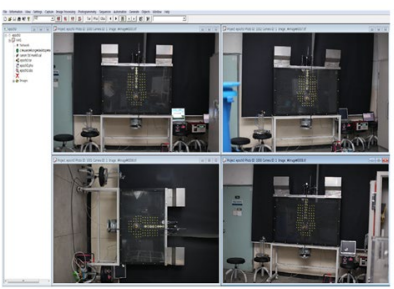

b

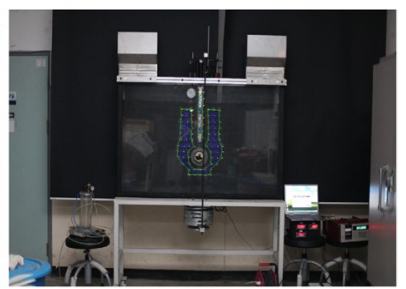

Fig. 9 Image processing programs: a VMS program; b EngVis program 
(reference points) are used in the image processing. Based on these control points, the positions of the target points in the soil can be identified. Consequently, these positions are plotted to $\mathrm{X}$ and $\mathrm{Y}$ coordinates by the VMS. In addition, based on these coordinates, a triangle mesh system is generated by the EngVis program (Fig. 9b).

\section{Results of model test}

Lee and Lee [9] definition of ultimate pile loads is used to determine an allowable pile load of $0.63 \mathrm{kN}$ (a safety factor of 3). The stages of $\mathrm{V}_{\mathrm{L}}$ are divided into 5: 0, 3, 5, 10 and $18 \%$. Settlements of pile and ground surface are increased according to the distance between the pile tip and tunnel crown (Fig. 10). Larger settlements of pile and ground surface occurred in case 1 for all $V_{L}$ steps than in any other case. The value of maximum ground $\mathrm{V}_{\mathrm{L}}$ due to tunnelling is $5 \%$ in general sandy ground. Therefore, the results are analysed according to the distance between the pile tip and tunnel crown with $\mathrm{V}_{\mathrm{L}}=3$ and $5 \%$. At this time, settlements of $\mathrm{V}_{\mathrm{L}}=0 \%$ are set to zero. As a result, when $\mathrm{V}_{\mathrm{L}}=3 \%$, the pile settlement of case 1 is $49.2 \%$ bigger than in case 2 and $58.7 \%$ bigger than in case 3 . The settlements of ground surface for case 1 increases $38 \%$ more than in case 2 , and $82 \%$ more than in case 3 . Also, the pile settlements increase by $23.2 \%$ for case 2 and $48.8 \%$ for case 3 . Settlements of ground surface rise by $35.2 \%$ for case 2 and $68.5 \%$ for case $3\left(V_{L}=5 \%\right)$. Table 1 shows settlements of pile and ground surface. The axial forces gradually increase from the pile crown until segment 3 but decrease under segment 3. Vertical displacements are concentrated around the embedded pile. Also, the total

a

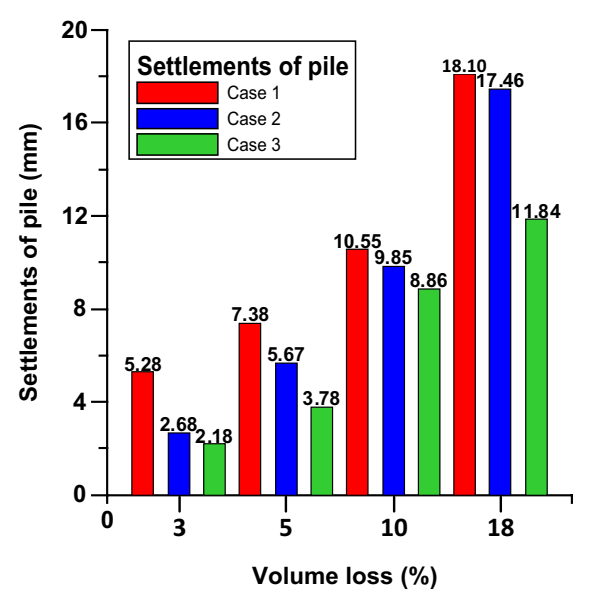

b

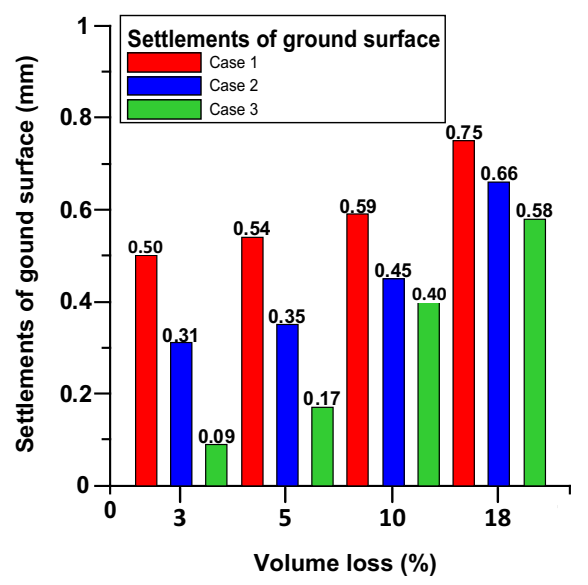

Fig. 10 Results of pile and ground surface settlements: a settlements of pile; $\mathbf{b}$ settlements of ground surface

Table 1 Settlements of pile and ground surface (unit: $\mathbf{m m}$ )

\begin{tabular}{llllllllllllll}
\hline Case & \multicolumn{1}{c}{ Case 1 } & \multicolumn{1}{c}{ Case 2 } & \multicolumn{1}{c}{ Case 3 } \\
\hline Volume loss $\left(\mathrm{V}_{\mathrm{L}}\right), \%$ & 3 & 5 & 10 & 18 & 3 & 5 & 10 & 18 & 3 & 5 & 10 & 18 \\
Pile & 5.28 & 7.38 & 10.55 & 18.10 & 2.68 & 5.67 & 9.85 & 17.46 & 2.18 & 3.78 & 8.86 & 11.84 \\
Ground surface & 0.50 & 0.54 & 0.59 & 0.75 & 0.31 & 0.35 & 0.45 & 0.66 & 0.09 & 0.17 & 0.40 & 0.58 \\
\hline
\end{tabular}


displacement vectors are observed around the pile and tunnel crown. Afterward, these results are compared using 3D numerical analyses.

\section{Numerical analysis}

A numerical analysis is conducted using Plaxis 3D [10]. The size of the embedded pile, tunnel, and containers are the same as in the model test. The allowable pile load is determined by an ultimate pile load of $1.9 \mathrm{kN}$ and a safety factor of 3 . Offsets between the pile tip and tunnel crown are classified in three cases, viz. 0.5D, 1.0D and 1.5D (Fig. 7).

\section{Material parameters}

Mohr-Coulomb and Linear elastic are applied to the model ground and piles, respectively. Material parameters of the soil and structures are shown in Table 2. Also, the interface factor (Rinter) is considered for accurate predictions [11-13].

\section{Results}

Vertical displacements are obviously concentrated around the embedded pile. The influence range of vertical displacements is expanded into the surrounding soil. The total displacement vectors are generated around the piles and tunnel. As the offset becomes closer, the displacements largely increase. The largest axial forces are generated in the third segment. This tendency is the same in the results of the model test.

\section{Comparison between model test and FE analysis}

\section{Comparison between model test and 3D numerical analysis}

The results of the model tests and numerical analyzes show similar trends. Figure 11a-c show settlements of pile and ground surface for 3 cases. In the results, $\delta(\max )$ means the maximum settlement of each $\mathrm{V}_{\mathrm{L}}$. $\delta(\mathrm{i})$ means initial settlements from the allowable pile load before tunnelling. As the offset between the pile tip and tunnel crown becomes closer, settlements of pile and ground surface increase. Also, settlement due to volume loss is largest in case 1 . As a result of $\mathrm{V}_{\mathrm{L}}=5 \%$, the pile settlements of case 1 is 7.3 and $15 \%$ bigger than in cases 2 and 3, respectively. In model test, the ground surface settlement of case 1 is 6.6 and $12.9 \%$ larger than case 2 and 3, respectively. Also, settlements of case 3 decreases by more than double compared to case 2 . In numerical analysis, the pile settlements increase by $14.3 \%$ for case 2 and $19.6 \%$ for case 3 . Settlements of ground surface rise by $1.9 \%$ for case 2 and $2.8 \%$ for case 3 . The largest axial force is measured in segment 3 in both the model test and numerical analysis (Fig. 12). However, the results

Table 2 Material parameters in FE analysis for the embedded pile and soil

\begin{tabular}{lll}
\hline Parameter & Soil & Pile \\
\hline$\gamma\left(\mathrm{kN} / \mathrm{m}^{3}\right)$ & 16 & 78.5 \\
$E\left(\mathrm{kN} / \mathrm{m}^{2}\right)$ & 1000 & $20,000,000$ \\
$V$ & 0.2 & 0.2 \\
$\mathrm{C}\left(\mathrm{kN} / \mathrm{m}^{2}\right)$ & 7 & - \\
$\Phi\left(^{\circ}\right)$ & 27 & - \\
$R_{\text {inter }}$ & 0.3 & \\
\hline
\end{tabular}

$\gamma$, unit weight of soil; E, Young's modulus; $v$, Poisson's ratio; c, cohesion; $\Phi^{\prime}$, Angle of shearing resistance; $R_{\text {inter }}$ interface factor 

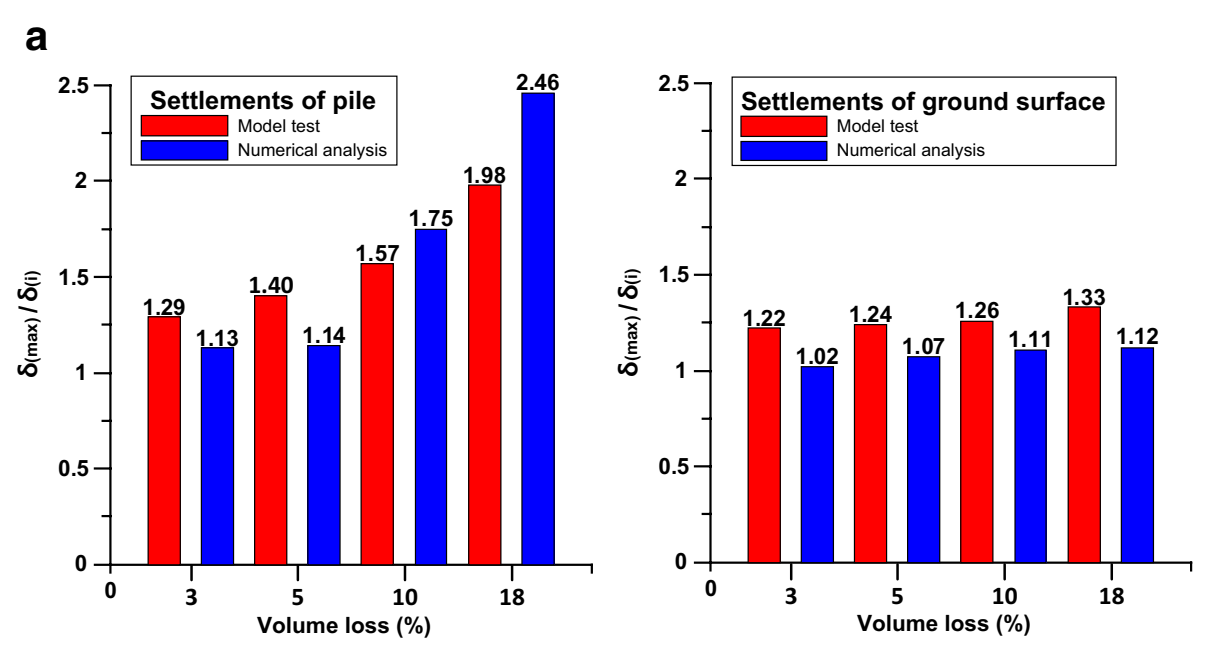

b
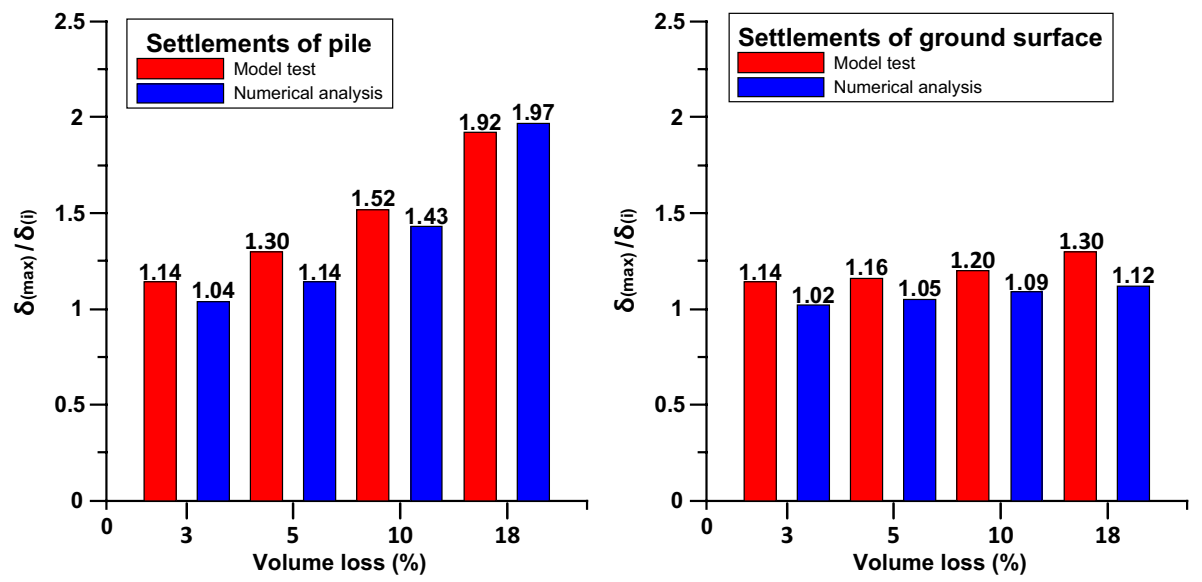

C
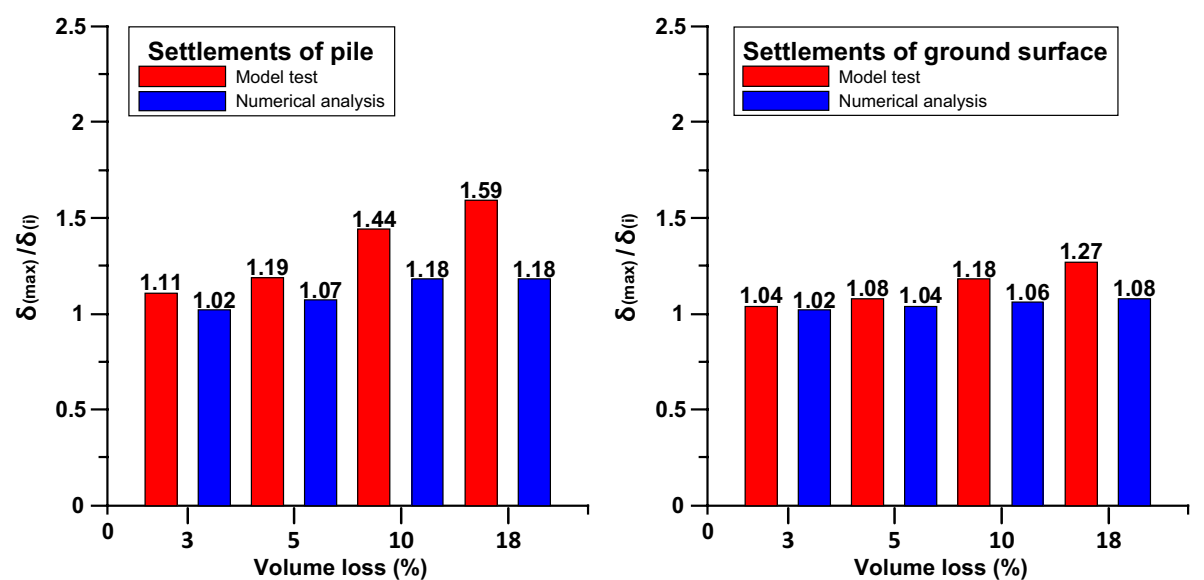

Fig. 11 Ground surface and pile settlement: a case 1; b case 2; c case 3 


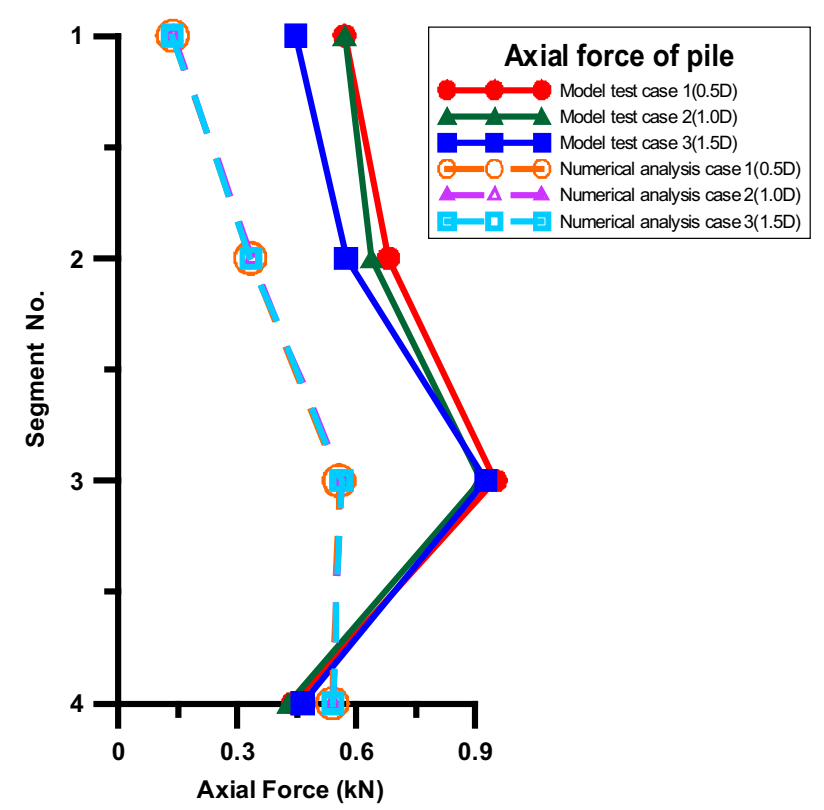

Fig. 12 Distribution of axial forces
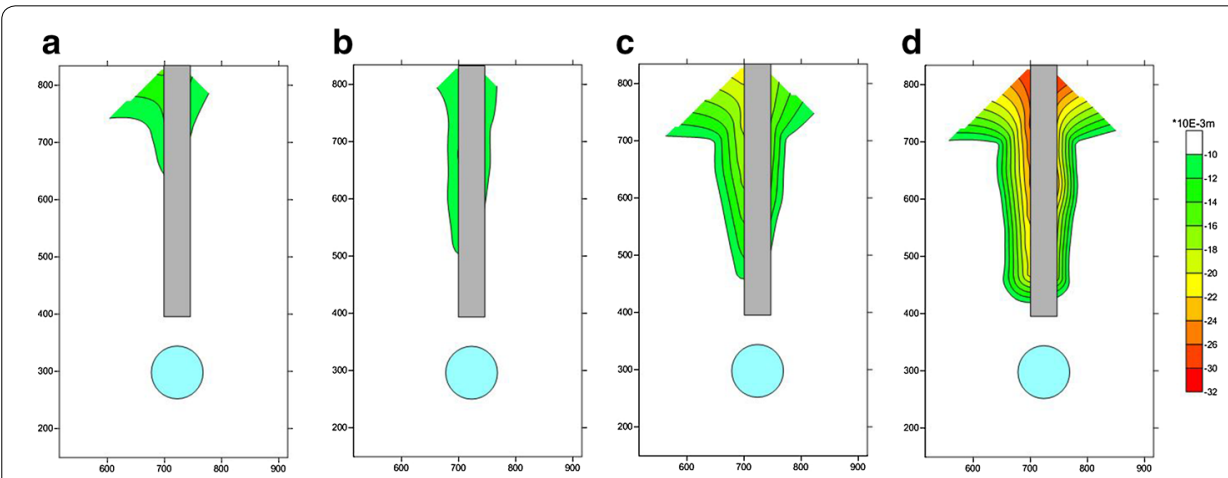

Fig. 13 Vertical displacements using close range photogrammetry (case $1: S=0.5 D$ ): $\mathbf{a} \vee_{L}=3 \% ; \mathbf{b} \vee_{L}=5 \%$; $\mathbf{c}$ $V_{L}=10 \% ; \mathbf{d} V_{L}=18 \%$
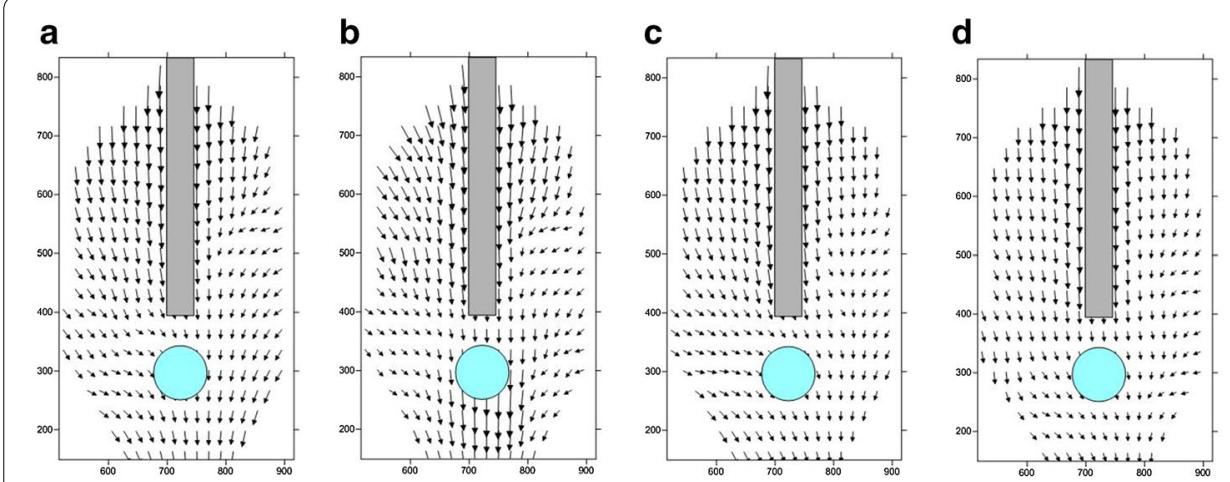

Fig. 14 Displacement vectors using close range photogrammetry (case 1: $S=0.5 \mathrm{D}$ ): $\mathbf{a} \vee_{L}=3 \% ; \mathbf{b} \vee_{L}=5 \%$; $\mathbf{c}$ $V_{L}=10 \% ; \mathbf{d} V_{L}=18 \%$ 

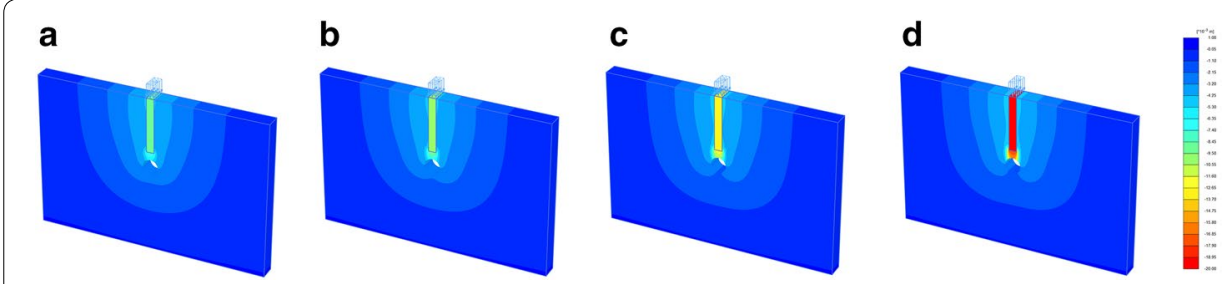

Fig. 15 Vertical displacements using $3 D$ numerical analysis (case $1: S=0.5 D$ ): $\mathbf{a} \vee_{L}=3 \% ; \mathbf{b} \vee_{L}=5 \%$; $\mathbf{c}$ $V_{L}=10 \% ; \mathbf{d} V_{L}=18 \%$

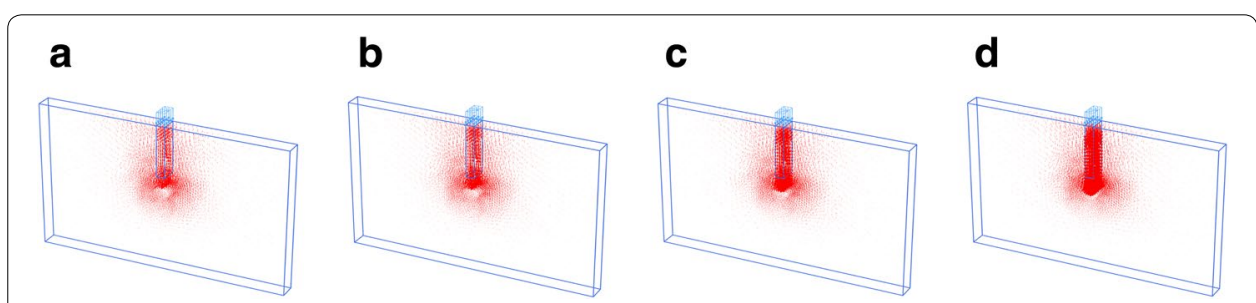

Fig. 16 Displacement vectors using $3 D$ numerical analysis (case $1: S=0.5 D$ ): $\mathbf{a} \vee_{L}=3 \% ; \mathbf{b} \vee_{L}=5 \%$; $\mathbf{c}$ $V_{L}=10 \% ; \mathbf{d} V_{L}=18 \%$
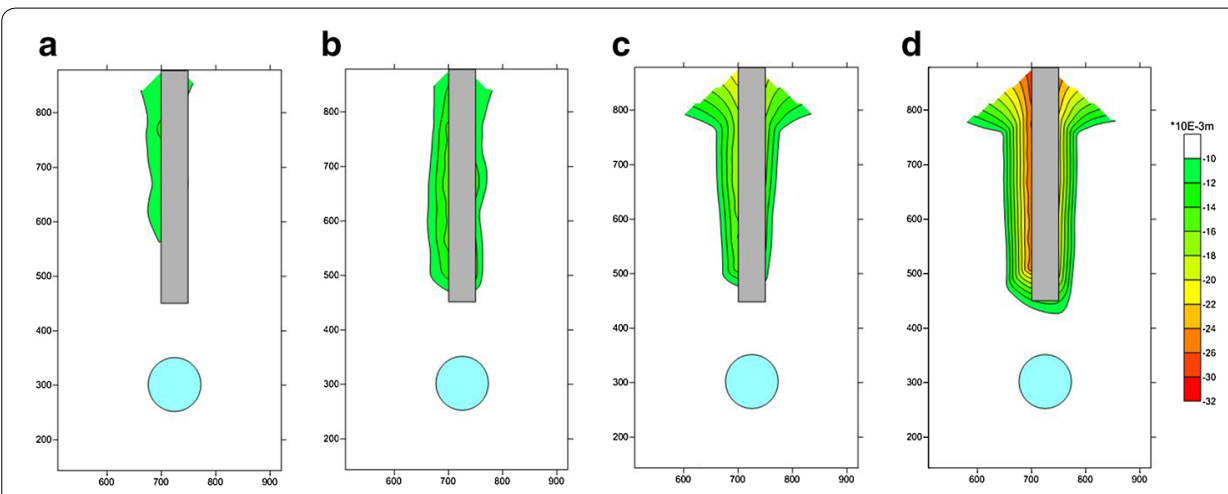

Fig. 17 Vertical displacements using close range photogrammetry (case $2: S=1.0 \mathrm{D}$ ): a $\vee_{L}=3 \% ; \mathbf{b} \vee_{L}=5 \%$; $\mathbf{c}$ $V_{L}=10 \% ; \mathbf{d} V_{L}=18 \%$
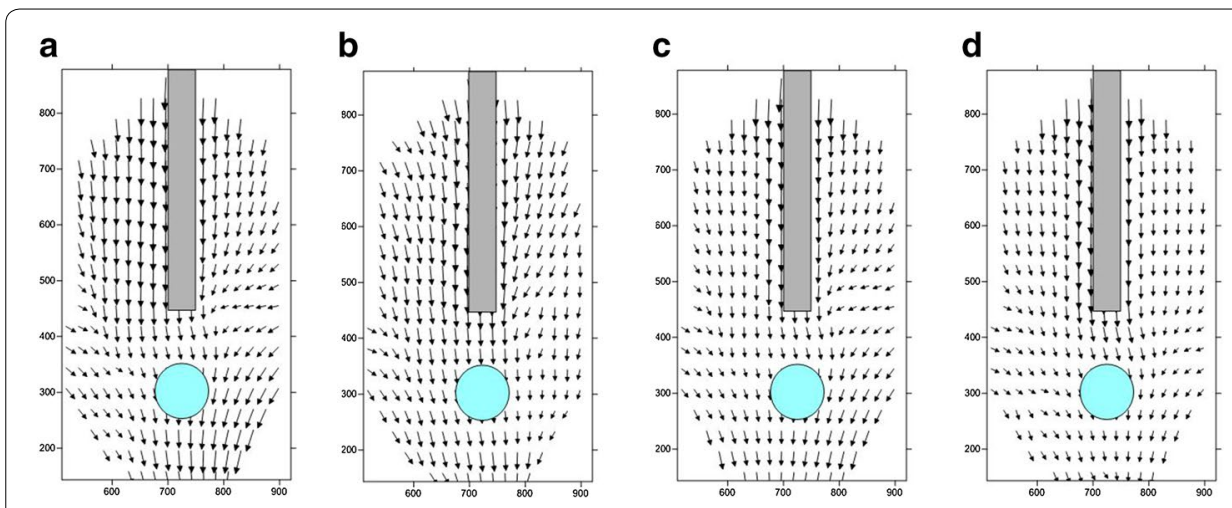

Fig. 18 Displacement vectors using close range photogrammetry (case $2: S=1.0 D$ ): $\mathbf{a} V_{L}=3 \% ; \mathbf{b} \vee_{L}=5 \%$; $V_{L}=10 \% ; \mathbf{d} V_{L}=18 \%$ 

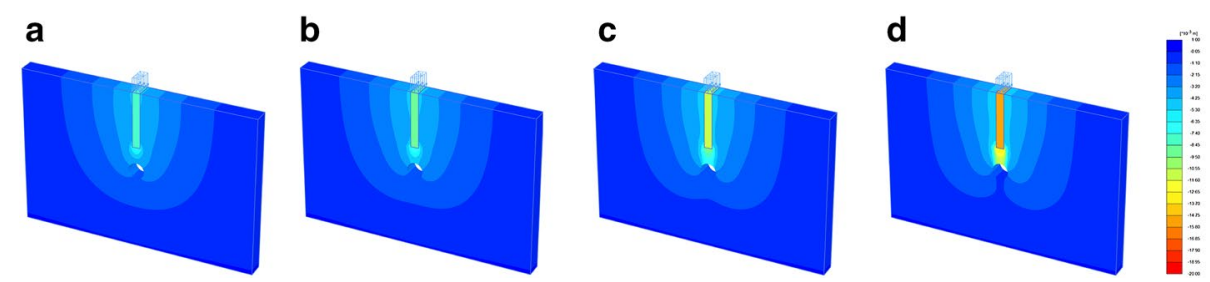

Fig. 19 Vertical displacements using $3 \mathrm{D}$ numerical analysis (case $2: S=1.0 \mathrm{D}$ ): $\mathbf{a} \vee_{\perp}=3 \% ; \mathbf{b} \vee_{L}=5 \% ; \mathbf{c}$ $V_{L}=10 \% ; \mathbf{d} V_{L}=18 \%$

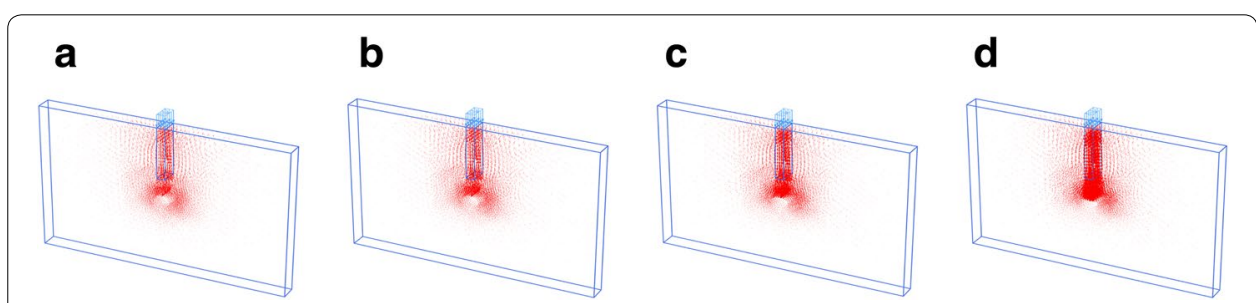

Fig. 20 Displacement vectors using 3D numerical analysis (case $2: S=1.0 D$ ): $\mathbf{a} V_{L}=3 \%$; b $V_{L}=5 \%$; $V_{L}=10 \% ; \mathbf{d} V_{L}=18 \%$
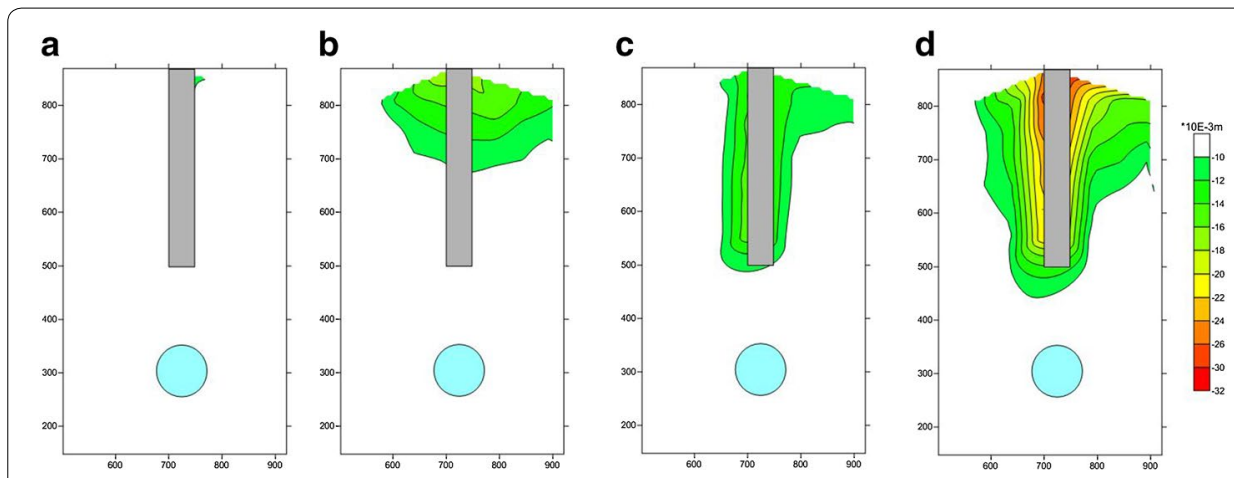

Fig. 21 Vertical displacements using close range photogrammetry (case $3: S=1.5 \mathrm{D}$ ): $\mathbf{a} \vee_{L}=3 \% ; \mathbf{b} \vee_{L}=5 \%$; $\mathbf{c}$ $V_{L}=10 \% ; \mathbf{d} V_{L}=18 \%$
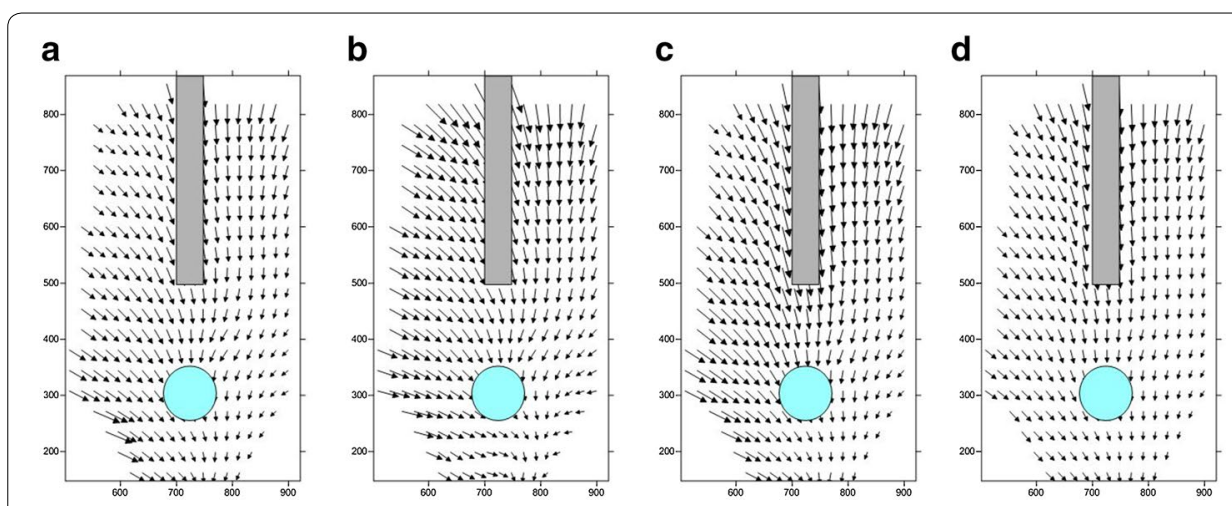

Fig. 22 Displacement vectors using close range photogrammetry (case $3: S=1.5 \mathrm{D}$ ): $\mathbf{a} \vee_{L}=3 \% ; \mathbf{b} \vee_{L}=5 \%$; $\mathbf{c}$ $V_{L}=10 \% ; \mathbf{d} V_{L}=18 \%$ 


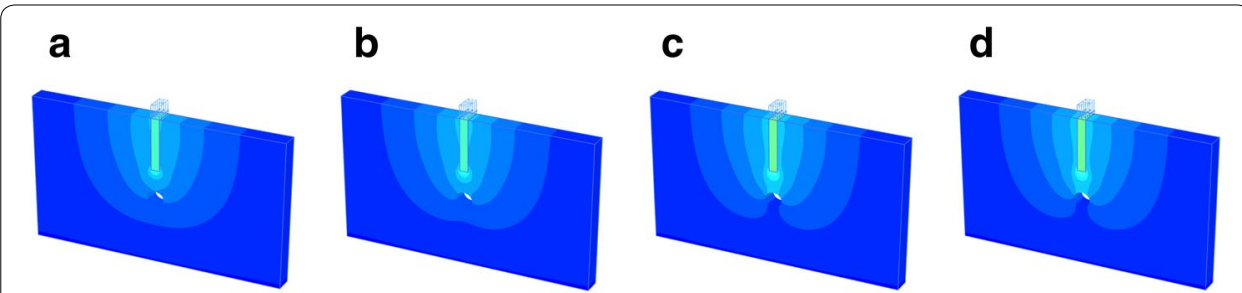

Fig. 23 Vertical displacements using 3D numerical analysis (case $3: S=1.5 D$ ): $\mathbf{a} \vee_{L}=3 \% ; \mathbf{b} \vee_{L}=5 \%$; $c$ $V_{L}=10 \% ; \mathbf{d} V_{L}=18 \%$

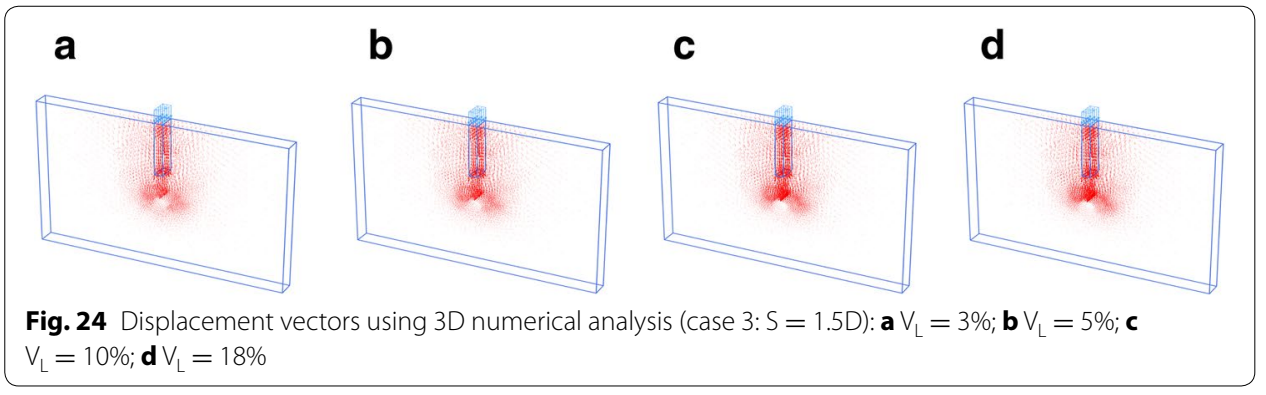

of the model test and numerical analysis differ slightly. This is because the load transfer affects the actual compaction, and also because of the size and shape of the soil particles.

\section{Comparison between close range photogrammetry and 3D numerical analysis}

Figures 13, 14, 15, 16, 17, 18, 19, 20, 21, 22, 23 and 24 show the results of cases 1,2 and 3 , respectively. Vertical displacements are largely concentrated around the pile in both the close range photogrammetry and numerical analysis. The influence range of vertical displacements is expanded to the ground surface. These vertical displacements increase with the closer distance between the pile tip and tunnel crown. They increase as the $V_{L}$ increases. The total displacement vectors go towards the tunnel crown. Consequently, large total displacement vectors can be observed at the pile sides and the tunnel crown.

\section{Conclusions}

In this study, the interactive behaviour between the embedded pile and its surrounding soil due to tunnelling is investigated. The offset between the piles and tunnel is considered in three cases, viz. 0.5D, 1.0D, 1.5D. The axial forces of each pile segment are measured in the model test. The behaviour of the ground is observed using close range photogrammetry and image processing. These results are compared to 3D numerical analysis. The conclusions of this study are summarized as follows:

1. The interactive behaviour between the pile and ground is observed according to various degrees of volume loss. Settlements are increased according to the increase of volume loss. As the offset between the pile tips and tunnel becomes closer, settlements of pile and ground surface increase. As a result of $\mathrm{V}_{\mathrm{L}}=3 \%$, the pile settlement of case 1 is 49.2 and $58.7 \%$ bigger than of cases 2 and 3, respectively. Also, the ground surface settlement of case 1 is 38 and $82 \%$ larger than cases 2 and 3, respectively. 
Also, for cases 2 and 3, the pile settlements increase to 23.2 and $48.8 \%$ and the settlements of ground surface rise to 35.2 and $68.5 \%$, at $\mathrm{V}_{\mathrm{L}}=5 \%$.

2. Results were compared according to offsets between the pile tip and tunnel crown at $\mathrm{V}_{\mathrm{L}}=5 \%$. Therefore, in this result, the value of $\delta(\max ) / \delta(\mathrm{i})$ in case 2 is twice the value of $\delta(\max ) / \delta(\mathrm{i})$ in case 3 in model test. In other words, the stability of the structure and ground significantly increases according to the offset.

3. The axial forces of the embedded pile segments are observed according to the distance of the tunnel crown and the end of the pile. The axial forces of the embedded pile rise continuously from the pile crown until the position of segment No. 3, and the axial forces under segment No. 3 gradually decrease. Consequently, the maximum load is observed at the position of segment No. 3. Further research about the relationship between axial forces and neutral axis is required.

4. The vertical displacements are concentrated at the side of the embedded pile. The contours of case 1 expand more than in other cases. The range of influence extends according to volume loss in both the close range photogrammetry and the numerical analysis. The total displacement vectors are observed around the pile and tunnel crown.

This study is helpful to understand the interactive behaviour between the pile and ground due to tunnelling; in particular, when the pile is located in the tunnel crown area. Further research using close range photogrammetry to analyse the results of shear strain will be carried out to help understand the failure of mechanisms.

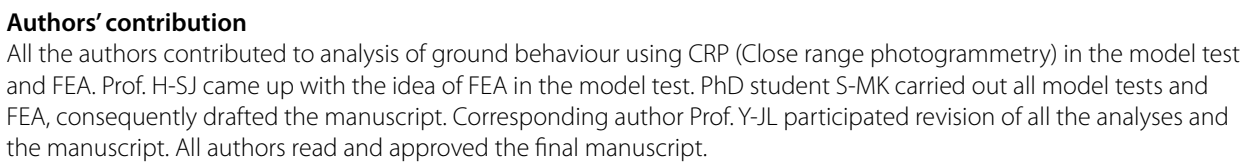

${ }^{1}$ Department of Civil Engineering, Seoul National University of Science and Technology, 232 Gongneung-ro, Nowon-gu, Seoul 139-743, South Korea. ${ }^{2}$ Department of Railroad Civil Engineering, Dongyang University, 145 Dongyangdae-ro, Punggi-eup, Yeongju, Gyeongsangbuk-do 36040, South Korea.

\section{Acknowledgements}

This study was supported by the basic science and engineering research program through the National Research Foundation of Korea (NRF-2013R1A1A2005101).

\section{Competing interests}

The authors declare that they have no competing interests.

Received: 8 February 2017 Accepted: 20 February 2017

Published online: 07 March 2017

\section{References}

1. Lee YJ (2013) Behaviour of embedded wall below tunnel centre line - model test and numerical analysis. Int J Geoengin 5(4):5-13

2. Lee CJ (2012) The response of a single and pile groups to tunneling performed in weathered rock. J Korean Soc Civil Eng 32(5):199-210

3. Yoo CS (2013) Interaction between tunneling and bridge foundation—a 3D numerical investigation. J Comput Geotech 49:70-78

4. Mair RJ, Williamson MG (2014) The influence of tunnelling and deep excavation on piled foundations. In: IS-Seoul 2014. Korean Geotechnical Society, Seoul, pp 21-30

5. Giardina G, DeJong MJ, Mair RJ (2014) Important aspects when modelling the interaction between surface structures and tunnelling in sand. In: IS-Seoul 2014. Korean Geotechnical Society, Seoul, pp 263-268

6. Franza A, Marshall AM, Haji T, Abdelatif AO, Carbonari S, Morici M (2017) A simplified elastic analysis of tunnel-piled structure interaction. J Tunn Undergr Space Technol 61:104-121 
7. Kwon HJ, Kim DS, Park JB, Jung SK (2011) Foundation engineering. Goomibook, Seoul, pp 223

8. Lee JH, Lee YJ (2014) Analysis of ground behavior for model tunnel excavation with pipe roof reinforcement using close range photogrammetric technique. J Korean Tunn Undergr Space Assoc 16(4):387-402

9. Lee JM, Lee YJ (2014) Investigation of pile behaviour according to interface properties-comparison between pile model test using close range photogrammetry and numerical analysis. J Korean Geotech Soc 30(9):29-39

10. Plaxis (2016) Plaxis 3D reference manual. Plaxis, pp 98-103

11. Lee JM, Lee YJ (2013) Load-settlement behaviour of pile according to interface properties using FEA. Int J Geoengin 5(1):21-30

12. Marshall AM, Haji T (2014) An analytical study of tunnel-pile interaction. J Tunn Undergr Space Technol 45:43-5

13. Park IJ, Kwak CW, Park JB (2012) Numerical modeling of static shear behavior in interfaces. Int J Geoengin 4(3):45-52

\section{Submit your manuscript to a SpringerOpen ${ }^{\circ}$} journal and benefit from:

- Convenient online submission

- Rigorous peer review

- Immediate publication on acceptance

- Open access: articles freely available online

- High visibility within the field

- Retaining the copyright to your article

Submit your next manuscript at $\boldsymbol{\nabla}$ springeropen.com 